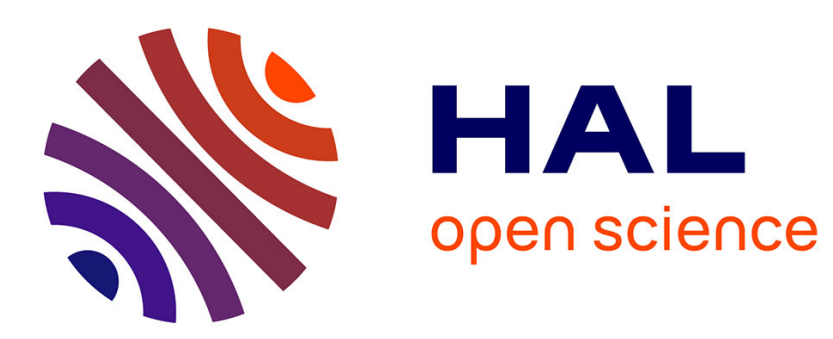

\title{
Gender Differences in the Influence of Mental Health on Job Retention
}

Thomas Barnay, Éric Defebvre

\section{To cite this version:}

Thomas Barnay, Éric Defebvre. Gender Differences in the Influence of Mental Health on Job Retention. LABOUR, 2019, 33 (4), pp.507-532. 10.1111/labr.12154 . hal-02112904

\section{HAL Id: hal-02112904 https://hal.science/hal-02112904}

Submitted on 27 Apr 2019

HAL is a multi-disciplinary open access archive for the deposit and dissemination of scientific research documents, whether they are published or not. The documents may come from teaching and research institutions in France or abroad, or from public or private research centers.
L'archive ouverte pluridisciplinaire HAL, est destinée au dépôt et à la diffusion de documents scientifiques de niveau recherche, publiés ou non, émanant des établissements d'enseignement et de recherche français ou étrangers, des laboratoires publics ou privés. 


\title{
GENDER DIFFERENCES IN THE INFLUENCE OF MENTAL HEALTH ON JOB RETENTION
}

\author{
Thomas Barnay ${ }^{1}$ and Éric Defebvre ${ }^{2}$
}

\begin{abstract}
We measure gender differences in the causal impact of the 2006 self-assessed mental health status (anxiety disorders and depressive episodes) on job retention in 2010. We use data from the French Health and Professional Career Path survey. To control for endogeneity biases, we use bivariate probit models to simultaneously explain employment status and mental health. Anxiety disorders reduce men's job retention capacity by up to 12 percentage points (pp). Depressive episodes affect both genders almost equally (around 11pp). More severe cases of both mental health conditions are relevant in determining the capacity of individuals to remain in employment.
\end{abstract}

JEL: I14, I18, C35, C36

Keywords: Mental health, Employment, Instrumental variables; Gender differences; France

\footnotetext{
${ }^{1}$ Érudite, Paris-Est University (UPE) and Tepp FR n³435-CNRS. Université Paris-Est Créteil, 61 avenue du Général de Gaulle, 94010 Créteil Cedex, France. barnay@u-pec.fr.

${ }^{2}$ Corresponding author. Centre d'Économie de la Sorbonne (CES), Paris 1 Panthéon-Sorbonne University and Tepp FR $n^{\circ}$ 3435-CNRS. Maison des Sciences Économiques, 106-112 boulevard de l'Hôpital, 75013 Paris, France. At the time of writing the first version Érudite, Paris-Est University (UPE). eric.defebvre@univ-paris1.fr.
} 


\section{INTRODUCTION}

Mental health problems cause reduced work productivity and increases in unemployment and sick-leaves. $40 \%$ of physical disabilities in high-income countries could be explained by mental disorders, according to the World Health Organization (2010).

In France, mental health (by which, we are referring to psychiatric disorders and psychotropic drug treatments, not the psychiatric pathologies identified in the health insurance database) accounts for $15 \%$ of France's statutory health insurance expenditures in 2011. This expenditure is greater than that of cancer treatments. According to the statutory health insurance database, more than seven million people suffer from psychiatric disorders in France. In addition, the Psychiatry and Mental Health Plan for 2011-2015 demonstrates the major role that mental health plays within current social issues. It explicitly states that access to - and retention in employment for individuals with mental illnesses requires better support. Yet, the issue of common mental disorders at work and the question of the role they play in workers' capacity to keep their job both remain mostly unaccounted for in France.

Thus, the issue of job retention, notably for people with mental disorders, appears to be essential in the current French public policy landscape. This has also been the case, since 2007, at the European level, as testified by the European commission on several occasions (EU strategy 2007-2012 - European Commission 2007). Regarding labour market outcomes, France is indeed characterized by a relatively low rate of employment among its working-age (between 15 and 64 years-old) population (64\% in 2010 vs. 64.4\% on average in OECD countries) and the rate of long-term unemployment remains very high (40\% vs. $31.4 \%$ in OECD). Part of the determinants of such low rates comes from a lack of support in terms of labour market inclusion, for workers facing health-related issues. For instance, a stronger than average detrimental effect of disabilities and cancers on job retention can be found in this country (Barnay et al., 2015). French workers also increasingly face the risk of losing their job, job security and job sustainability thus appearing as a growing concern for policy makers.

In the international economic literature, gender differences in the effect of mental health on employment outcomes also appear relatively unclear and are subject of debates. When most studies find a detrimental effect of mental health disorders on men's employment (Ojeda et al., 2010; Zhang et al., 2009), it is rarely the case on women's. Yet, some studies do find an effect in the female population, sometimes even greater than in their male counterparts (Frijters et al. 2014). 
In this economic literature, the relationship between mental health and employment is subject to several methodological issues (Barnay, 2016). Most importantly, a precarious job situation can affect mental health, inducing reverse causality problems when studying the role of mental health on employment outcomes: being unemployed may indeed generate the feeling of losing one's social utility and of a growing social isolation, leading to mental health deterioration. Self-reported health indicators are also characterized by justification biases and measurement errors, as well as by social heterogeneity (i.e., the same objective health status is reported differently, depending on individual characteristics such as gender, age or general health status) (Akashi-Ronquest et al., 2011; Etilé and Milcent, 2006; Shmueli, 2003). As with physical health status, selection effects are also at work. Mental health measurements are also potentially subject to a specific selection bias related to the psychological inability to answer questionnaires.

Our goal is to measure the causal impact of mental health on job retention using French data, with a specific focus on gender differences. This study is inspired by Jusot et al. (2008), who measure the impact that physical health and risky behaviours have on the probability of leaving employment four years later. Our main contribution to the existing literature comes from the analysis of how anxiety disorders and depressive episodes impact men and women differently when it comes to their employment outcomes. Notably, we implement several mental health indicators, based on both the disorders' nature and intensity. To acknowledge the endogeneity biases in the relationship, we also use gender-differentiated econometric frameworks. Also, to the best of our knowledge, no French study has empirically measured the specific effect of such mental health indicators on employment while addressing endogeneity biases and considering gender differences.

To do so, we use data coming from the Santé et Itinéraire Professionnel survey (Health and Professional Career Path - SIP), which allows us to collect from 2006 a set of indicators (socioeconomic characteristics, health and risky behaviours). We also rely on the career characteristics from a complete retrospective questionnaire on the employment and health events of more than 13,000 individuals. A temporal dimension is allowed by a second wave conducted in 2010. The basis of our mental health indicators consists of self-reported measurements for generalized anxiety disorders (GAD) and major depressive episodes (MDE), as well as different intensities of these disorders. Using bivariate probit and two-stage least squares models, we evaluate the causal effect that self-reported mental health in 2006 had on employment in 2010 after controlling for reverse causality. We notably find that men suffering 
from anxiety disorders experience a drop in their capacity to remain in employment by up to 12 percentage points (pp) while no such effect can be found in women. Anxiety becomes significantly associated with job retention in women when considering more severe cases. Both men and women declaring depressive episodes see their probability to remain in employment drop by at least 10pp.

Our article is organized as follows. We present a literature review on the main empirical results regarding the links between mental health and several employment outcomes. We then describe the dataset and empirical strategy. A final section presents the results and concludes.

\section{LITERATURE REVIEW}

The economic literature establishing the role of mental health in employment faces many methodological problems such as measurement errors and endogeneity biases. Studies employ two definitions of mental health. The first one focuses on heavy mental disorders, such as psychoses (Bartel and Taubman, 1986) or schizophrenia (Greve and Nielsen, 2013). The second one is based on more common but less disabling disorders such as stress or depression (Chang and Yen, 2011; Dahal and Fertig, 2013; Frijters et al., 2014; Kessler et al., 2001; Zhang et al., 2009). However, due to the risk of simplification arising from the use of aggregate scores, indicators of generalized anxiety disorders and major depressive episodes were therefore preferred (Banerjee et al., 2015; Chatterji et al., 2011) (see Appendix 1 and Appendix 2). Furthermore, the relationship between mental health and employment is bidirectional and thus leads to reverse causality problems (Banerjee et al., 2015; Chatterji et al., 2011). In particular, being unemployed may impair the mental health of individuals (Mossakowski, 2009). Other factors are related to both mental health and employment, such as risk preferences (Zhang et $a l ., 2009$ ), workers' involvement at work and the ability to give satisfaction (Nelson and Kim, 2008), personality traits, family background (Banerjee et al., 2015), and risky behaviours (smoking, alcohol and overweight). These factors remain unobservable for the most part in household surveys and therefore act as confounders. Finally, it is possible to highlight some justification biases. Individuals may alter their health status declarations directly in the presence of the interviewer in order to rationalize their choices in the labour market (Zhang et al., 2009). Lindeboom and Kerkhofs (2009 used Dutch panel data and fixed effects models to show that economic incentives are likely to distort health status declarations. This also seems to be the case in Ireland, after controlling for unobserved heterogeneity (Gannon, 2009). 
Whatever the mental health indicators, studies converge towards a detrimental role of bad mental health in employment outcomes. Thus, Banerjee et al. (2015) find that people suffering from mental disorders (major depressive episodes and generalized anxiety disorders) are much less likely to be in employment than others at the time of the survey. Chatterji et al. (2011) use cross-sectional data and rely on two-stage and Altonji Elder Taber modelling (Altonji et al., 2005). After taking into account unobserved heterogeneity, they find that mental disorders reduce the likelihood of being in employment by an average of $15 \%$. One American study resorts to instrumental variable methods to find that most people with mental disorders are in employment, but more pronounced symptoms reduce their participation in the labour market (Ojeda et al., 2010). Finally, simultaneous modelling on Taiwanese pooled data confirms that poor mental health decreases the probability of working. They specify that the prevalence of these disorders is lower among workers, thus inducing a protective effect of work on mental health (Chang and Yen, 2011). These average effects are heterogeneous according to age and sex. Zhang et al. (2009) find that mental health-related discrimination in the labour market is greater for middle-aged workers than for older workers. Sex effects are also important. The role of mental disorders in employment seems stronger in men (Ojeda et al., 2010; Zhang et al., 2009), but Frijters et al. (2014) notably show a stronger effect of mental health on women's employment based on Australian panel data and several models, including bivariate Probit and fixed effects approaches.

In order to handle endogeneity biases, the literature usually makes use of instrumental variables and panel data models. Frijters et al. (2014) used the death of a close friend as an instrument for mental health. Hamilton et al. (1997) used stressful events in life, the regularity of sport activity and a lagged mental health indicator, the latter of which was also used by (Banerjee et al., 2015). The psychological status of parents (Ettner et al., 1997; Marcotte et al., 2000), that of the children (Chatterji et al., 2011; Ettner et al., 1997), and social support (Alexandre and French, 2001; Hamilton et al., 1997; Ojeda et al., 2010) were also frequently introduced. These factors were often used because they are important determinants of mental health. They also meet the validity assumption, which states that they are not directly correlated with the outcome, either because of their temporal distance from the other factors explaining employment or because of their absence of direct effects on employment. We make use of this literature by choosing proxies of mental health during childhood (violence suffered during this period and having been raised by a single parent), as well as by using indicators for psychological status and social support during adult life (marital breakdowns). Furthermore, we also take a different 
approach according to gender. In these ways, we place some temporal distance between these events and employment status (events occurring during childhood are observed up to age 18, whereas our working sample includes only individuals aged 20 and older; marital ruptures occur before 2006, i.e., four years before the outcome). There is also a low probability of direct effects of these instruments on the employment status of 2010, as we also control for the professional career path characteristics and employment at the time of the survey.

\section{EMPIRICAL APPROACH}

2.1. The Santé et Itinéraire Professionnel survey

The Santé et Itinéraire Professionnel (SIP) survey used in this study provides access to particularly detailed individual information. Aside from the usual socioeconomic variables (age, sex, activity sector, professional category, educational level, and marital status), specific items are provided in regard to physical and mental health. The survey was designed jointly by the French Ministries of Healthcare and Labour, and it includes two waves (2006 and 2010). These were conducted on the same sample of people aged 20-74 living in private households in European France (thus excluding overseas French territories). Two questionnaires are available: The first was administered by an interviewer and provides accurate information on the respondents' individual and job characteristics as well as their current health status. It also contains a biographical lifegrid to reconstruct individual careers and life events: childhood, education, health, career changes, working conditions and significant life events. The second one is a self-administered questionnaire targeting risky health behaviours (weight, cigarette and alcohol consumption). It notably provides information on current or past tobacco and alcohol consumption (frequency, duration, etc.). A total of 13,648 people were interviewed in 2006, and 11,016 of them again in 2010 .

In this study, we focus on people who responded to the survey both in 2006 and 2010, i.e., 11,016 individuals. We select individuals aged 20-55 who were in employment in 2006 (see Appendix 3 for a note on attrition between the two waves). The final sample thus consists of 4,981 individuals, including 2,368 men and 2,613 women.

\subsection{Variables}

In this study, the dependant variable is individual employment status in 2010. Specifically, this binary variable takes the value 1 to indicate if individuals are in employment in 2010 and 0 if not (in cases of unemployment or inactivity). Note that this variable indicates whether employed individuals in 2006 are also in employment in 2010, but not if they are still in the same job. 
We measure mental health by using major depressive episodes (MDE) and generalized anxiety disorder (GAD), from the Mini International Neuropsychiatric Interview (MINI). These two indicators of mental health have been used in previous studies, notably in Banerjee et al. (2015) and Chatterji et al. (2011). These two binary variables indicate whether individuals suffer from anxiety or depression, respectively, based on two specific algorithms outlined in the Diagnostic and Statistical Manual of Mental disorders (DSM-IV), which are described in Appendix 1 and Appendix 2. There is no difference in algorithms according to other individual characteristics such as gender. These variables take the value 1 when one suffers from a generalized anxiety disorder (or from a major depressive episode), and 0 otherwise. These indicators prove particularly robust in describing mental health in the SIP survey (see Appendix 4). Note that we built these mental health indicators as suggested by the MINI for the main specifications. Further consideration will be put into how they are built as a robustness check (Section 3.3.1). We also make use of several indicators of individual characteristics that were declared in 2006. Notably, we use age, age squared (continuous variables) and a set of binary variables: being in a relationship at the time of the survey, having at least one child living in the household, and level of education (no diploma or primary education, the equivalent of the French baccalauréat or superior education levels). We also account for employment characteristics in 2006: professional category (farmer, artisan, manager, intermediate, employee and blue collar); activity status (private sector, public sector or self-employed); activity sector (agricultural, industrial or services); and whether the respondent declared working part-time or not. Two retrospective indicators for the whole career are included: The first is a binary indicator showing that individuals spent more than half of their careers in jobs lasting more than 5 years (stable jobs); the second one shows whether individuals had a stable career (i.e., between 0 and 3 transitions across four different states: employment spans lasting more than 5 years, employment spans lasting less than a year, unemployment spans of more than a year and inactivity spans of more than a year).

\subsection{Descriptive statistics}

Table 1 below shows that 5\% (resp. 6\%) of individuals in employment in 2006 report suffering from generalized anxiety disorders (resp. major depressive episodes). These prevalences are very close to what can be found in France for this time period when we look at other datasets that use the same algorithms for GAD and MDE (Beck et al., 2010 - also, see Appendix 4 for more details). It is also noteworthy that our sample's proportion of individuals in employment in 2006 who were still employed four years later is $91 \%$, with important differences depending 
on one's mental health state. This proportion indeed drops to $85 \%$ (resp. 83\%) for individuals suffering from GAD (resp. MDE).

Table 1: General descriptive statistics

\begin{tabular}{|c|c|c|c|c|c|c|c|c|c|c|}
\hline \multirow{2}{*}{ Variable } & \multirow{2}{*}{ Mean } & \multirow{2}{*}{ SER } & \multirow{2}{*}{ Min } & \multirow{2}{*}{ Max } & \multicolumn{3}{|c|}{ Anxiety disorder (GAD) } & \multicolumn{3}{|c|}{ Depressive episode (MDE) } \\
\hline & & & & & GAD & None & Diff. & MDE & None & Diff. \\
\hline \multicolumn{11}{|l|}{ Mental health in 2006} \\
\hline Suffering from anxiety disorder & .05 & .22 & 0 & 1 & - & - & - & - & - & - \\
\hline Suffering from depressive episode & .06 & .24 & 0 & 1 & - & - & - & - & - & - \\
\hline \multicolumn{11}{|l|}{ Employment status in 2010} \\
\hline In employment & .91 & .28 & 0 & 1 & .85 & .92 & $.07 * * *$ & .83 & .92 & $.09 * * *$ \\
\hline \multicolumn{11}{|l|}{ Ind. characteristics in 2006} \\
\hline Male & .48 & .50 & 0 & 1 & .30 & .49 & $.19 * * *$ & .28 & .49 & $.21 * * *$ \\
\hline Age & 42.03 & 8.50 & 20 & 55 & 42.06 & 42.02 & -.03 & 43.65 & 41.92 & $-1.72 * * *$ \\
\hline In a relationship & .82 & .38 & 0 & 1 & .71 & .82 & $.12 * * *$ & .66 & .83 & $.18 * * *$ \\
\hline Children & .13 & .34 & 0 & 1 & .13 & .13 & -.00 & .11 & .13 & .02 \\
\hline \multicolumn{11}{|l|}{ Education } \\
\hline - No diploma & .05 & .22 & 0 & 1 & .03 & .05 & $.03 * *$ & .06 & .05 & -.01 \\
\hline - $\quad$ Primary & .45 & .50 & 0 & 1 & .48 & .45 & -.03 & .53 & .45 & $-.08 * * *$ \\
\hline - French Baccalauréat & .18 & .38 & 0 & 1 & .17 & .18 & .01 & .18 & .18 & -.00 \\
\hline - $\quad$ Superior & .31 & .46 & 0 & 1 & .33 & .30 & -.02 & .23 & .31 & $.09 * * *$ \\
\hline \multicolumn{11}{|l|}{ Employment in 2006} \\
\hline \multicolumn{11}{|l|}{ Professional category } \\
\hline - Farmers & .03 & .16 & 0 & 1 & .02 & .03 & $.01 *$ & .03 & .03 & .00 \\
\hline - $\quad$ Artisans & .05 & .22 & 0 & 1 & .04 & .05 & .01 & .08 & .05 & $-.03 *$ \\
\hline - $\quad$ Managers & .14 & .35 & 0 & 1 & .12 & .14 & .02 & .10 & .14 & $.05 * * *$ \\
\hline - Intermediate & .25 & .43 & 0 & 1 & .26 & .25 & -.01 & .20 & .26 & $.05 * *$ \\
\hline - Employees & .30 & .46 & 0 & 1 & .37 & .29 & $-.07 * *$ & .39 & .29 & $-.10 * * *$ \\
\hline - Blue collar & .22 & .41 & 0 & 1 & .17 & .22 & $.05^{*}$ & .19 & .22 & .03 \\
\hline \multicolumn{11}{|l|}{ Activity status } \\
\hline - Private & .65 & .48 & 0 & 1 & .65 & .65 & -.00 & .63 & .65 & .01 \\
\hline - $\quad$ Public sector & .27 & .44 & 0 & 1 & .27 & .27 & -.00 & .27 & .27 & .00 \\
\hline - Self-employed & .08 & .28 & 0 & 1 & .08 & .08 & .00 & .10 & .08 & -.02 \\
\hline \multicolumn{11}{|l|}{ Act. sector } \\
\hline - Agricultural & .06 & .24 & 0 & 1 & .05 & .06 & .02 & .05 & .06 & .01 \\
\hline - Industrial & .16 & .37 & 0 & 1 & .13 & .16 & .03 & .15 & .16 & .01 \\
\hline - Services & .78 & .42 & 0 & 1 & .82 & .78 & $-.05 *$ & .80 & .78 & -.03 \\
\hline Part time & .83 & .37 & 0 & 1 & .73 & .84 & $.11 * * *$ & .74 & .84 & $.10^{* * *}$ \\
\hline \multicolumn{11}{|l|}{ Professional Career Path } \\
\hline Maj. of empl. in long jobs & .77 & .42 & 0 & 1 & .71 & .78 & $.07 * *$ & .75 & .78 & .03 \\
\hline Stable career path & .74 & .44 & 0 & 1 & .70 & .75 & .04 & .69 & .75 & $.06^{* *}$ \\
\hline
\end{tabular}

Note: Standard errors in italics. ***: significant at 1\%, **: significant at 5\%, *: significant at $10 \%$.

Source: Santé et Itinéraire Professionnel survey, individuals aged 20-55 in employment in 2006.

\subsection{Econometric strategy}

\subsubsection{Estimating the role of mental health on job retention: naïve models}

The econometric strategy is based on two steps to correct individual heterogeneity and reverse causality. In the first step, we initiate binomial univariate probit models to estimate - from among people in employment in 2006 - the correlation between mental health in 2006 and employment in 2010 (dependant variable $y_{i, 2010}$ ). We run separated regressions according to gender due to strong gendered differences in mental health, which are notably linked to different conceptions of one's own health status (Artazcoz et al., 2004; Devaux et al., 2008; Leach et al., 2008). 
The specification explains job retention between 2006 and 2010 by mental health status in 2006 $\left(M H_{i, 2006}\right)$, after controlling for a set of standard socioeconomic variables $\left(S E_{i, 2006}^{\prime}\right)$ as well as professional path characteristics $\left(P R_{i}^{\prime}\right)$ :

$$
\begin{gathered}
y_{i, 2010}^{*}=\alpha+\beta M H_{i, 2006}+\gamma S E_{i, 2006}^{\prime}+\omega P R_{i}^{\prime}+\varepsilon_{i} \\
y_{i, 2010}=\mid \begin{array}{l}
1 \text { if } y_{i, 2010}^{*}>0 \\
0 \text { if } y_{i, 2010}^{*} \leq 0
\end{array}
\end{gathered}
$$

Depending on the specification, mental health in 2006 is represented by a binary variable that takes either the value 1 when individual $i$ is suffering from a generalized anxiety disorder or 0 otherwise; or, likewise, by a binary variable that takes either the value 1 when individual $i$ is suffering from a major depressive episode or 0 otherwise.

Socio-economic variables (in 2006) include age, age squared, being in a relationship, having at least one child living in the household, level of education, professional category, activity status (private sector, public sector or self-employed), activity sector (agricultural, industrial or services) and part-time work. Age plays a major role in employability and in reporting behaviours for mental disorders (Devaux et al., 2008; Shmueli, 2003). Current marital status and the presence of children in the household can also affect both employability (especially in women) and reported mental health, since people in relationships with children turn out to have better health status (Artazcoz et al., 2004; Plaisier et al., 2008). Work characteristics are also relevant in determining the probability of being employed at a given time (Llena-Nozal et al., 2004).

Retrospective variables include spending more than half of one's career in jobs lasting more than 5 years and the number of transitions in the labour market between periods of employment, unemployment and inactivity. Our objective is to control the results of potentially unstable careers (state-dependence phenomenon) that may lead to greater fragility in the labour market (Kelly et al., 2011; Mossakowski, 2009).

\subsubsection{Endogeneity biases and instrumental variables strategy}

However, as widely explained in the literature, our mental health variables potentially suffer from endogeneity biases. First, employment status and mental health influence each other (Banerjee et al., 2015; Chatterji et al., 2011). For instance, being unemployed may impair one's mental health (Mossakowski, 2009), notably due to the feeling of losing one's social utility and to experiencing growing social isolation. This case of reverse causality is nonetheless ruled out 
as most unlikely in our study, since there is a time gap between our measures of mental health (2006) and those of employment (2010). Also, in regard to state dependency induced by past employment status being related to subsequent mental health and current employment status (i.e., past labour market instability leading to current instability and mental impairments): this is mitigated by taking into account the nature of the past professional career (and the de facto 2006 employment status). Nevertheless, some individual characteristics are not included in our model although they are linked not only to employment but also to the declaration of mental health. Namely, these are: risk preferences (Zhang et al., 2009) ; involvement at work and the ability to give satisfaction (Nelson and Kim, 2008) ; personality traits and family background (Banerjee et al., 2015). Due to these omitted confounders, we are thus likely to be in the presence of endogenous mental health variables due to omitted cofounders.

In order to take into account this endogeneity issue, we set up a bivariate probit model. As suggested by the literature (Chatterji et al., 2011; Frijters et al., 2014; Ojeda et al., 2010), we rely on a methodology that uses bivariate probit modelling estimated by maximum likelihood. The two simultaneous equations to estimate can be written as follows:

$$
\begin{gathered}
y_{i, 2010}^{*}=\alpha+\beta M H_{i, 2006}+\gamma S E_{i, 2006}^{\prime}+\omega P R_{i}^{\prime}+\varepsilon_{i} \\
M H_{i, 2006}^{*}=\alpha^{\prime}+\gamma^{\prime} S E_{i, 2006}^{\prime}+\omega^{\prime} P R_{i}^{\prime}+\varepsilon_{i}^{\prime} \\
y_{i, 2010}=\left|\begin{array}{l}
1 \text { if } y_{i, 2010}^{*}>0 \\
0 \text { if } y_{i, 2010}^{*} \leq 0
\end{array} \quad M H_{i, 2006}=\right| \begin{array}{l}
1 \text { if } M H_{i, 2006}^{*}>0 \\
0 \text { if } M H_{i, 2006}^{*} \leq 0
\end{array}
\end{gathered}
$$

where $\varepsilon_{i}$ and $\mu_{i}$ are the respective residuals for esquations (2) and (3). Despite the inclusion of these control variables, it is likely that the residuals of these two equations are correlated, thus inducing $\rho=\operatorname{Corr}\left(\varepsilon_{i}, \varepsilon_{i}^{\prime} \mid S E_{i, 2006}^{\prime}, P R_{i}^{\prime}\right) \neq 0$.

It indeed seems possible that there are unobserved factors that affect not only mental health conditions but also the capacity to remain employed, such as individual preferences or personality traits. Notably, an unstable employment path before 2006 is one of the explanatory factors of mental health in 2006 as well as of employment status in 2010 (state dependence). Thus, estimating only equation (1) would result in omitting part of the actual model. In such a case, a bivariate probit model is required in the presence of binary outcome and explanatory variables (Lollivier, 2006).

A new specification (4) is therefore implemented, and it simultaneously explains mental health by means of three instrumental variables (vector Ident ${ }_{i}^{\prime}$ ): 


$$
\begin{gathered}
\left\{\begin{array}{l}
y_{i, 2010}^{*}=\alpha+\beta M H_{i, 2006}+\gamma S E_{i, 2006}^{\prime}+\omega P R_{i}^{\prime}+\varepsilon_{i} \\
M H_{i, 2006}^{*}=\alpha^{\prime}+\theta \text { Ident }_{i}^{\prime}+\gamma^{\prime} S E_{i, 2006}^{\prime}+\omega^{\prime} P R_{i}^{\prime}+\varepsilon_{i}^{\prime}
\end{array}\right. \\
y_{i, 2010}=\left\{\begin{array}{l}
1 \text { if } y_{i, 2010}^{*}>0 \\
0 \text { if } y_{i, 2010}^{*} \leq 0
\end{array} \quad M H_{i, 2006}=\mid \begin{array}{l}
1 \text { if } M H_{i, 2006}^{*}>0 \\
0 \text { if } M H_{i, 2006}^{*} \leq 0
\end{array}\right.
\end{gathered}
$$

The model assumes that the error terms follow a bivariate normal distribution:

$$
\left[\begin{array}{c}
\varepsilon_{i} \\
\varepsilon_{i}^{\prime}
\end{array}\right] \rightarrow N\left[\left(\begin{array}{l}
0 \\
0
\end{array}\right),\left(\begin{array}{ll}
1 & \rho \\
\rho & 1
\end{array}\right)\right]
$$

In order to ensure that the results obtained are robust, we also estimate the main specification using OLS and 2SLS estimators, thus relying on linear probability models (LPM). The main advantages are: first, the $F$ statistic of the first stage regression can be computed; second, the coefficient of interest is very easy to interpret; and, third, the non-linearity itself in non-linear models may also have an influence on the coefficient of interest. Yet, it is possible that the coefficient estimates may not be included in the $[0 ; 1]$ interval.

\subsubsection{Instrumental variables}

In theory, it is possible to estimate bivariate probit models without resorting to instrumental variables (exclusion condition). However, the empirical literature generally prefers to base estimates on the exclusion criterion and use instrumental variables. These variables must follow two well-known hypotheses. The relevance assumption states that the instrumental variables must be correlated with the endogenous variable that one wishes to instrument, which in our case is anxiety and depression. Then, the validity assumption induces that the instrumental variables are not directly correlated with the dependant variable: employment status in 2010 . The instrumental variable set that we use is taken from SIP's lifegrid. We use three binary variables: having been raised by a single parent up until age 18 (taking the value 1 when this is the case, and 0 otherwise); having suffered from violence during childhood at the hand of relatives or in school up until age 18 (taking the value 1 when this is the case, and 0 otherwise); having experienced at least one marital breakdown during adult life up to 2006 (taking the value 1 when this is the case, and 0 otherwise).

We differentiate our instruments by sex: for men, we retain having suffered violence and marital breakdowns; for women, having suffered violence and having been raised by a single parent. This choice is motivated by the fact that we want to make use of the strongest determinants of mental health for each group. For instance, having been raised by a single parent is not a particularly strong determinant of men's mental health in our sample, so it does not appear as 
intrinsically relevant to instrument men's mental health. Then, marital breakdowns are much more likely to be related to women's outcomes on the labour market than to men's, hence rendering doubtful the use of such a variable as an exogenous instrument for the women subsample. For these two reasons, we decided to adopt a differentiated instrumental variable approach for men and women. The results obtained with this differentiated strategy are more precisely estimated, the instruments being more correlated with our mental health indicators and less likely to challenge the exogeneity hypothesis. Yet, it is noteworthy that these results remain mostly unchanged (same sign and relatively comparable significance levels) when implementing a more conventional approach using all three instruments for both genders. Using a binary endogenous variable of mental health, there is no real specialized test to assess the validity of our instrumental variables. Also, to our knowledge, no other study linking mental health with employment outcomes made use of such framework. Yet, from a theoretical standpoint and for several reasons, we believe our instrumental variables are relevant in determining mental health while they are not directly correlated with employment outcomes in 2010.

Being raised by a single parent and suffering violence are observed during childhood, i.e., before age 18. Because our individuals are at least 20 years of age or older in 2006, quite some time has passed between possible violence faced during childhood / having been raised by a single parent and the employment situation in 2010. Thus, because we choose to retain only individuals in employment in 2006, we most likely drop individuals who are the most exposed/impacted by such characteristics in terms of employment outcomes. On top of that, it is not likely that such characteristics may have a direct impact on employment status in 2010, conditionally to the control variables used in this study. It is indeed more likely that the roles these characteristics could play in employment arise more notably from educational attainments and their subsequent stability among career paths, which are all accounted for. Thus, while being able to predict mental health (Dalgard et al., 2006; Kelly et al., 2011; Llena-Nozal et al., 2004), we believe that these instrumental variables also fit the exclusion criterion.

We also use the fact of having faced at least one marital breakdown as an important life event and as a proxy for a loss in social support, as both of them are often shown in the literature to be detrimental factors for mental health (Alexandre and French, 2001; Hamilton et al., 1997; Ojeda et al., 2010). Because it is declared in the 2006 wave of the SIP survey, there is at least a decent time gap between the last marital breakdown (happening in 2006 at the latest) and the evaluation of employment in 2010. Still, marital breakdowns may impact workers' 
employability for three main reasons: 1) Non-working partners may start to work after breaking up in order to make ends meet. Yet, because for this study we are interested only in individuals who are in employment in 2006, this point is accounted for de facto. 2) They may have to change work because of greater/different needs after breaking up. This is mitigated by the fact that we control for several elements of their 2006 professional situation (part time, activity sector, etc.) and elements of their professional career (being mostly in long-term jobs, stable career), meaning that any pre-2006 changes in their job/employment situations due to a pre2006 marital breakdown should not directly impact their employment situation in 2010. 3) After breaking up, ex-partners may face problems with depression, self-esteem, self-confidence, and instability, among other disorders, thus leading to poorer outcomes in the labour market. This is accounted for mostly by the fact that such elements are part of the mental health indicator itself and hence, by themselves, do not bear any direct consequence on employment outcomes (i.e., consequences that are not part of our mental health indicators). Yet, we cannot completely rule out that at least a small part of the variance induced by these unobservable characteristics is directly related to employment, regardless of our mental health indicators.

\section{RESULTS}

\subsection{Univariate results}

The univariate models presented in Table 2 for generalized anxiety disorders and Table 3 for major depressive episodes show that men and women suffering from GAD or MDE in 2006 are less likely to remain in employment in 2010. Men in employment and who declare suffering from anxiety in 2006 are on average 9 percentage points $(p p)$ less likely to remain in employment in 2010, according to the probit estimations. Depression seems to bear very similar consequences. In the female population, however, no statistically relevant impact of anxiety can be found on the probability of being employed in 2010, while facing depression slightly decreases this probability $(-3 p p)$. These main univariate results are confirmed by their linear counterparts. This appears to be in line with most of the literature (Chatterji et al., 2011; Ojeda et al., 2010; Zhang et al., 2009) that finds greater impact of mental health as a whole on men's employment.

However, the other determinants of employment often differ between men and women, which is in agreement with what other French studies have observed (Barnay, 2010). In women, the predictors of job retention four years later are age $(+3 p p)$, the presence of children $(-6 p p)$, the fact of working in the service sector $(+6 p p)$ in comparison to the industrial sector and to 
working part-time $(-3 p p)$. Having worked in long-term jobs is beneficial to employment $(+3 p p)$. This is also the case for stable jobs $(+5 p p)$. It is interesting to note that within this selected population (i.e., those in employment in 2006), professional categories play no role in employment trajectory between 2006 and 2010. The significant factors for poorer labour market performance in men are age $(+3 p p)$, lack of education, celibacy and professional category (blue collar workers are most likely to leave the labour market compared to farmers and managers). 
Table 2: Effect of anxiety disorders on the estimated probability of employment in 2010

\begin{tabular}{|c|c|c|c|c|c|c|c|c|c|c|c|c|c|c|c|c|}
\hline \multirow{3}{*}{ Variable } & \multicolumn{8}{|c|}{ Men } & \multicolumn{8}{|c|}{ Women } \\
\hline & \multicolumn{2}{|c|}{ Probit } & \multicolumn{2}{|c|}{ Biprobit } & \multicolumn{2}{|c|}{ OLS } & \multicolumn{2}{|c|}{ 2SLS } & \multicolumn{2}{|c|}{ Probit } & \multicolumn{2}{|c|}{ Biprobit } & \multicolumn{2}{|c|}{ OLS } & \multicolumn{2}{|c|}{ 2SLS } \\
\hline & Coeff. & SER & Coeff. & SER & Coeff. & SER & Coeff. & SER & Coeff. & SER & Coeff. & SER & Coeff. & SER & Coeff. & SER \\
\hline \multicolumn{17}{|l|}{ Mental health in 2006} \\
\hline Suffering from anxiety disorder & $-.09 * * *$ & .02 & $-.12 * * *$ & .03 & $-.11 * * *$ & .03 & $-.15 * * *$ & .03 & -.03 & .02 & -.06 & .05 & -.03 & .05 & -.07 & .06 \\
\hline \multicolumn{17}{|l|}{ Ind. characteristics in 2006} \\
\hline Age & $.03 * * *$ & .02 & $.03 * * *$ & .02 & $.05 * * *$ & .01 & $.05 * * *$ & .01 & $.03 * * *$ & .01 & $.03 * * *$ & .01 & $.03 * * *$ & .01 & $.03 * * *$ & .01 \\
\hline Age squared & $-.00 * * *$ & .00 & $-.00 * * *$ & .00 & $-.00 * * *$ & .00 & $-.00 * * *$ & .00 & $-.00 * * *$ & .00 & $-.00 * * *$ & .00 & $-.00 * * *$ & .00 & $-.00 * * *$ & .00 \\
\hline In a relationship (ref.: Single) & $.03 * *$ & .01 & $.03 * *$ & .01 & $.04 * *$ & .02 & .02 & .02 & .01 & .01 & .01 & .01 & .01 & .01 & .01 & .02 \\
\hline Children (ref.: None) & -.03 & .02 & -.03 & .02 & -.02 & .02 & -.02 & .02 & $-.06 * * *$ & .02 & $-.06 * * *$ & .02 & $-.06 * * *$ & .02 & $-.06 * * *$ & .02 \\
\hline \multicolumn{17}{|l|}{ Education (ref.: French bac.) } \\
\hline - No diploma & $-.07 * * *$ & .02 & $-.07 * * *$ & .02 & $-.08 * * *$ & .03 & $-.10 * * *$ & .03 & -.03 & .03 & -.03 & .03 & -.03 & .03 & -.03 & .03 \\
\hline - $\quad$ Primary & $-.03 *$ & .02 & $-.03 *$ & .02 & $-.03 *$ & .02 & -.03 & .02 & -.02 & .02 & -.02 & .02 & -.02 & .02 & -.02 & .02 \\
\hline - $\quad$ Superior & .00 & .02 & .00 & .02 & -.01 & .02 & -.01 & .02 & -.01 & .02 & -.01 & .02 & -.01 & .02 & -.01 & .02 \\
\hline \multicolumn{17}{|l|}{ Employment in 2006} \\
\hline \multicolumn{17}{|l|}{ Prof. cat. (ref.: Blue collar) } \\
\hline - Farmers & $.14 * *$ & .05 & $.14^{* *}$ & .05 & $.11 * *$ & .04 & .08 & .05 & .03 & .07 & .03 & .07 & .03 & .06 & .03 & .06 \\
\hline - Artisans & $.10 * *$ & .04 & $.10 * *$ & .04 & $.08 * * *$ & .03 & .06 & .04 & -.01 & .04 & -.01 & .04 & -.00 & .04 & -.00 & .04 \\
\hline - Managers & $.04 * *$ & .02 & $.04 * *$ & .02 & $.05 * *$ & .02 & .05 & .02 & .01 & .03 & .01 & .03 & .02 & .03 & .02 & .03 \\
\hline - $\quad$ Intermediate & .01 & .01 & .01 & .01 & .02 & .02 & .02 & .02 & -.00 & .02 & -.00 & .02 & .00 & .02 & .00 & .02 \\
\hline - Employees & -.00 & .02 & -.00 & .02 & -.00 & .02 & -.01 & .02 & .01 & .02 & .01 & .02 & .02 & .02 & .02 & .02 \\
\hline \multicolumn{17}{|l|}{ Activity status (ref.: Private) } \\
\hline - Public sector & .02 & .02 & .02 & .02 & .02 & .02 & .02 & .02 & .01 & .01 & .01 & .01 & .01 & .01 & .01 & .01 \\
\hline - $\quad$ Self-employed & .03 & .03 & .03 & .03 & .03 & .03 & .05 & .04 & .05 & .03 & .05 & .03 & .04 & .03 & .04 & .03 \\
\hline \multicolumn{17}{|l|}{ Act. sector (ref.: Industrial) } \\
\hline - $\quad$ Agricultural & -.03 & .02 & -.03 & .02 & -.03 & .03 & -.03 & .03 & .05 & .04 & .05 & .04 & .06 & .04 & .06 & .04 \\
\hline - Services & .00 & .01 & .00 & .01 & .00 & .01 & .01 & .02 & $.06 * * *$ & .02 & $.06 * * *$ & .02 & $.08 * * *$ & .02 & $.08 * * *$ & .02 \\
\hline Part time (ref.: Full-time) & -.04 & .03 & -.04 & .03 & $-.06 *$ & .04 & $-.07 *$ & .04 & $-.03 * *$ & .01 & $-.03 * *$ & .01 & $-.03 * *$ & .01 & $-.03 *$ & .01 \\
\hline \multicolumn{17}{|l|}{ Professional Career Path } \\
\hline Maj. of empl. in long jobs & $.05 * * *$ & .02 & $.05 * * *$ & .02 & $.03 * *$ & .02 & .03 & .02 & $.03 * *$ & .01 & $.03 * *$ & .01 & $.02 *$ & .01 & $.02 *$ & .01 \\
\hline Stable career path & .00 & .01 & .00 & .01 & .01 & .01 & .01 & .01 & .01 & .01 & .01 & .01 & .00 & .01 & .00 & .01 \\
\hline Rho & & & $.42 * *$ & .18 & & & & & & & .46 & .39 & & & & \\
\hline F-stat & & & & & & & & & & & & & & & & \\
\hline $\mathbf{N}$ & & & & & & & & & & & & & & & & \\
\hline
\end{tabular}

Note: Marginal effects, standard errors in italics. ***: significant at 1\%, **: significant at 5\%, *: significant at 10\%.

Source: Santé et Itinéraire Professionnel survey, individuals aged 20-55 in employment in 2006. 
Table 3: Effect of depressive episodes on the estimated probability of employment in 2010

\begin{tabular}{|c|c|c|c|c|c|c|c|c|c|c|c|c|c|c|c|c|}
\hline \multirow{3}{*}{ Variable } & \multicolumn{8}{|c|}{ Men } & \multicolumn{8}{|c|}{ Women } \\
\hline & \multicolumn{2}{|c|}{ Probit } & \multicolumn{2}{|c|}{ Biprobit } & \multicolumn{2}{|c|}{ OLS } & \multicolumn{2}{|c|}{ 2SLS } & \multicolumn{2}{|c|}{ Probit } & \multicolumn{2}{|c|}{ Biprobit } & \multicolumn{2}{|c|}{ OLS } & \multicolumn{2}{|c|}{ 2SLS } \\
\hline & Coeff. & SER & Coeff. & SER & Coeff. & SER & Coeff. & SER & Coeff. & SER & Coeff. & SER & Coeff. & SER & Coeff. & SER \\
\hline $\begin{array}{l}\text { Mental health in } 2006 \\
\text { Suffering from depressive } \\
\text { episode }\end{array}$ & $-.09 * * *$ & .02 & $-.11 * * *$ & .03 & $-.12 * * *$ & .03 & $-.14 * * *$ & .05 & $-.03 *$ & .02 & $-.10 * *$ & .04 & $-.04 * *$ & .02 & $-.12 * *$ & .06 \\
\hline \multicolumn{17}{|l|}{ Ind. characteristics in 2006} \\
\hline Age & $.03 * * *$ & .02 & $.03 * * *$ & .02 & $.05 * * *$ & .01 & $.05 * * *$ & .01 & $.03 * * *$ & .01 & $.03 * * *$ & .01 & $.03 * * *$ & .01 & $.03 * * *$ & .01 \\
\hline Age squared & $-.00 * * *$ & .00 & $-.00 * * *$ & .00 & $-.00 * * *$ & .00 & $-.00 * * *$ & .00 & $-.00 * * *$ & .00 & $-.00 * * *$ & .00 & $-.00 * * *$ & .00 & $-.00 * * *$ & 00 \\
\hline In a relationship (ref.: Single) & $.03 * *$ & .01 & $.03 * *$ & .01 & $.03 * *$ & .02 & -.04 & .05 & .01 & .01 & .01 & .01 & .01 & .01 & .00 & .02 \\
\hline Children (ref.: None) & -.03 & .02 & -.03 & .02 & -.02 & .02 & -.01 & .03 & $-.06 * * *$ & .02 & $-.06 * * *$ & .02 & $-.05 * * *$ & .02 & $-.05^{* * *}$ & .02 \\
\hline \multicolumn{17}{|l|}{ Education (ref.: French bac.) } \\
\hline - $\quad$ No diploma & $-.07 * * *$ & .02 & $-.07 * * *$ & .02 & $-.08 * * *$ & .03 & $-.08 * *$ & .03 & -.03 & .03 & -.03 & .03 & -.03 & .03 & -.03 & .03 \\
\hline - $\quad$ Primary & $-.03 *$ & .02 & $-.03 *$ & .02 & $.03 *$ & .02 & -.02 & .02 & -.03 & .02 & -.03 & .02 & -.02 & .02 & -.02 & .02 \\
\hline - $\quad$ Superior & .00 & .02 & .00 & .02 & -.01 & .02 & -.02 & .02 & -.01 & .02 & -.01 & .02 & -.01 & .02 & -.01 & .02 \\
\hline \multicolumn{17}{|l|}{ Employment in 2006} \\
\hline \multicolumn{17}{|l|}{ Prof. cat. (ref.: Blue collar) } \\
\hline - Farmers & $.15^{* *}$ & .05 & $.15^{* *}$ & .05 & $.12 * * *$ & .04 & $.11^{* *}$ & .05 & .03 & .07 & .03 & .07 & .04 & .06 & .04 & .06 \\
\hline - Artisans & $.11 * *$ & .04 & $.11 * *$ & .04 & $.09 * * *$ & .03 & $.11^{* *}$ & .04 & -.00 & .04 & -.00 & .04 & .00 & .04 & .00 & .04 \\
\hline - $\quad$ Managers & $.04 * *$ & .02 & $.04 * *$ & .02 & $.04 * *$ & .02 & .04 & .03 & .01 & .03 & .01 & .03 & .02 & .03 & .02 & .03 \\
\hline - $\quad$ Intermediate & .01 & .01 & .01 & .01 & .02 & .02 & .02 & .02 & -.01 & .02 & -.01 & .02 & .00 & .02 & .00 & .02 \\
\hline - $\quad$ Employees & -.00 & .02 & -.00 & .02 & -.00 & .02 & -.02 & .03 & .01 & .02 & .01 & .02 & .02 & .02 & .02 & .02 \\
\hline \multicolumn{17}{|l|}{ Activity status (ref.: Private) } \\
\hline - $\quad$ Public sector & $.03^{*}$ & .02 & $.03^{*}$ & .02 & $.03^{*}$ & .02 & $.04 *$ & .02 & .01 & .01 & .01 & .01 & .01 & .01 & .01 & .01 \\
\hline - $\quad$ Self-employed & .02 & .03 & .02 & .03 & .02 & .03 & .03 & .04 & .05 & .03 & .05 & .03 & .04 & .03 & .04 & .03 \\
\hline \multicolumn{17}{|l|}{ Act. sector (ref.: Industrial) } \\
\hline - $\quad$ Agricultural & -.03 & .02 & -.03 & .02 & -.03 & .03 & -.02 & .04 & .04 & .04 & .04 & .04 & .06 & .04 & .06 & .05 \\
\hline - $\quad$ Services & .00 & .01 & .00 & .01 & .00 & .01 & .01 & .02 & $.06^{* * *}$ & .02 & $.06 * * *$ & .02 & $.08 * * *$ & .02 & $.08 * * *$ & .02 \\
\hline Part time (ref.: Full-time) & -.04 & .03 & -.04 & .03 & -.06 & .04 & -.07 & .05 & $-.03 * *$ & .01 & $-.03 * *$ & .01 & $-.03 * *$ & .01 & $-.03 * *$ & .01 \\
\hline \multicolumn{17}{|l|}{ Professional Career Path } \\
\hline Maj. of empl. in long jobs & $.05 * * *$ & .02 & $.05^{* * *}$ & .02 & $.04 * *$ & .02 & .03 & .02 & $.03 * *$ & .01 & $.03^{* *}$ & .01 & $.02 *$ & .01 & $.02 *$ & .01 \\
\hline Stable career path & .00 & .01 & .00 & .01 & .00 & .01 & -.02 & .02 & .01 & .01 & .01 & .01 & .01 & .01 & .01 & .01 \\
\hline Rho & \multirow{3}{*}{\multicolumn{2}{|c|}{2,368}} & $.53 * *$ & .15 & & & \multirow{3}{*}{\multicolumn{2}{|c|}{$\begin{array}{l}12.41 \\
2,368 \\
\end{array}$}} & \multirow{3}{*}{\multicolumn{2}{|c|}{2,613}} & $.48 * *$ & .20 & & & \multirow{3}{*}{\multicolumn{2}{|c|}{$\begin{array}{l}19.67 \\
2,613\end{array}$}} \\
\hline F-stat & & & & & & & & & & & & & & & & \\
\hline $\mathbf{N}$ & & & & & & & & & & & & & & & & \\
\hline
\end{tabular}

Note: Marginal effects, standard errors in italics. ***: significant at 1\%, **: significant at 5\%, *: significant at $10 \%$.

Source: Santé et Itinéraire Professionnel survey, individuals aged 20-55 in employment in 2006. 


\subsection{Instrumented mental health}

Table 2 and Table 3 also present the results of the bivariate probit and 2SLS estimates for, respectively, generalized anxiety disorders and major depressive episodes (the results of the simultaneous biprobit equations and the first-stages of the 2SLS regressions are available in Table 7 and Table 8, Appendix 5). For these results, only two instrumental variables are used for men and women: having suffered from violence during childhood (men and women), having experienced at least one marital breakdown (men only) and having been raised by a single parent (women only). All things being equal, the three instrumental variables are good predictors of mental health disorders as we measure them. Facing violence during childhood and having at least one marital breakdown in men increase the probability of experiencing anxiety in 2006 by, respectively, $8 p p$ and $2 p p$. This is also the case for predicting depression (respectively, $+5 p p$ and $+4 p p$ ). In women, experiencing violence before age 18 and being raised by a single parent increase the probability of anxiety by $7 p p$ and $2 p p$ and the probability of depression by $10 p p$ and $5 p p$. These results are confirmed by the linear regressions.

Using these instrumental variables should allow us to establish a causal relationship between mental health and employment retention. The correlation coefficients $(\rho)$ between the residuals of the two simultaneous biprobit model equations of appear to be statistically significant and rather elevated in all cases except in women for the anxiety model. In addition, the first-stage $F$ statistics given by the 2 SLS results always appear at least slightly above the rule-of-thumb threshold of 10, thus reinforcing our confidence in our instrumental strategy (Table 2, Table 3, Table 7 and Table 8 in Appendix 5). In men, the causal effect of mental health in 2006 on employment in 2010 seems increased by the bivariate analysis, now indicating a drop of $12 p p$ induced by anxiety and a drop of $11 p p$ linked to depression in the probability of remaining at work. This increase in marginal effects linked to instrumental variables is much more sizeable in women suffering from depression, with a decrease of $10 p p$ in the depression-related probability of remaining in employment. Yet, still no effect linked to anxiety can be found. The marginal effects for the control variables remain the same, and the linear probability models (2SLS) confirm these results. Even though the IV marginal effects appear to be relatively greater in magnitude than their univariate counterparts, they are still quite similar. We believe that this is the case thanks to the 4-year time gap between the evaluation of mental health (2006) and that of employment (2010), thus guarding against reverse causality. Also, because we control for a diverse set of individual and job characteristics, as well as very global past career 
elements, endogeneity linked to unobserved heterogeneity might not have been too major prior to instrumentation.

\subsection{Robustness checks}

To assess the robustness of our results, we conducted several robustness checks. We tested whether the differences in the effect of mental health on job retention between men and women were confirmed using other mental health specifications. We considered other age groups ${ }^{3}$ as well as a shorter temporal distance between mental health and employment (it indeed may be questionable to measure the role of poor mental health on employment four years later).

\subsubsection{Gender heterogeneity}

Some of the differences found between men and women in terms of the role of mental health in employment might come from the fact that one's declaration of suffering from GAD or MDE does not have the same meaning for these populations. For instance, men might under-declare that they face such mental issues due to social pressure; and women, in contrast, might overdeclare these due to being more conscious about their own health. -Both of these situations follow the usual health declaration pattern that is widely discussed in the literature (Devaux et al., 2008; Shmueli, 2003). If this is the case, then men actually declaring GAD or MDE might be facing more extreme cases of these troubles than women declaring them, thereby inducing more important consequences on men's employment outcomes. This is a possibility, notably because the Mini-International Neuropsychiatric Interview (MINI) does not handle men and women differently in its algorithms. To rephrase this hypothesis, one could say that the latent threshold to be reached for one to declare such mental health issues is higher in men than in women.

We decided to decompose GAD and MDE into their respective components to rebuild the thresholds needed to be considered ill instead of relying on the thresholds used by the MINI (as described in Appendix 1 and Appendix 2). Table 4 below gives the econometric results on job retention obtained using four new thresholds of mental health for men and women as well as by using probit and bivariate probit estimators. The calculations for each of these thresholds are as follows. Low major depressive episodes consist of facing at least two symptoms related to MDE, and high major depressive episodes of at least six symptoms related to MDE (instead of at least five symptoms for the MINI version). Low generalized anxiety disorders are those in

\footnotetext{
${ }^{3}$ Sensitivity tests were performed by estimating the models on the 25-50, 30-50 and 25-55 years-old groups. These tests, not presented here, confirm our results in all cases.
} 
which respondents face at least two symptoms related to GAD, and high generalized anxiety disorders have at least seven symptoms related to GAD (instead of at least six symptoms for the MINI version). Each model estimates one of these four indicators separately and controls for all covariates that are used in the paper. Thus, the estimations are run separately according to gender and mental health indicator.

Table 4: Low and high mental disorder thresholds (one specification per threshold, per disorder type)

\begin{tabular}{|c|c|c|c|c|c|c|c|c|}
\hline \multirow{3}{*}{ Variable } & \multicolumn{4}{|c|}{ Men } & \multicolumn{4}{|c|}{ Women } \\
\hline & \multicolumn{2}{|c|}{ Probit } & \multicolumn{2}{|c|}{ Biprobit } & \multicolumn{2}{|c|}{ Probit } & \multicolumn{2}{|c|}{ Biprobit } \\
\hline & Coeff. & SER & Coeff. & SER & Coeff. & SER & Coeff. & SER \\
\hline \multicolumn{9}{|l|}{ Mental health specifications: GAD } \\
\hline Low anxiety disorder & $-.04 * * *$ & .01 & $-.06 * *$ & .03 & -.01 & .02 & -.02 & .04 \\
\hline High anxiety disorder & $-.11 * * *$ & .02 & $-.14 * * *$ & .03 & $-.04 *$ & .02 & $-.08 * *$ & .04 \\
\hline \multicolumn{9}{|l|}{ Mental health specifications: MDE } \\
\hline Low depressive episode & $-.05 * *$ & .02 & $-.07 * *$ & .03 & -.01 & .02 & -.05 & .04 \\
\hline High depressive episode & $-.12 * * *$ & .02 & $-.15 * *$ & .03 & $-.05 *$ & .02 & $-.13 * * *$ & .05 \\
\hline Control variables & \multicolumn{2}{|c|}{ Yes } & \multicolumn{2}{|c|}{ Yes } & & & \multicolumn{2}{|c|}{ Yes } \\
\hline $\mathbf{N}$ & \multicolumn{4}{|c|}{2,368} & \multicolumn{4}{|c|}{2,613} \\
\hline
\end{tabular}

Note: Marginal effects, standard errors in italics. ***: significant at 1\%, **: significant at 5\%, *: significant at $10 \%$.

Source: Santé et Itinéraire Professionnel survey, individuals aged 20-55 in employment in 2006.

It should be noted that the marginal effects for control variables in Table 4 are almost the same in comparison to the main specifications; thus, they are not presented here. The results indicate that being exposed to more symptoms in men systematically increases the marginal effect of mental health on job retention. Probit estimates indicate that facing low GAD decreases men's probability to remain in employment by $4 p p$, and by up to $11 p p$ for high GAD. The results are comparable for MDE. Using bivariate probit models, the results tend to increase, which is in line with the main results of the paper. More interestingly, new effects on women can be found. According to probit estimates, facing low GAD does not have any consequence on job retention, but high GAD does and amounts to $-4 p p$. This is similar for MDE. Bivariate probit models indicate even higher effects. These new results tend to confirm that the absence of a GAD effect in women's capacity to remain in employment is likely to come from heterogeneity in their declaration of mental health problems in comparison to men's.

\subsubsection{An employment indicator over the period 2007-2010}

Our measurement of the impact of mental health on employment outcomes can be potentially subject to biases, given the duration of the observation period. It might indeed be doubtful that the mental health status of 2006 alone could still bear significant consequences four years later: career paths and mental health between 2006 and 2010 could have instead been significantly affected by the effects of economic conditions (notably the economic crisis of 2009), regardless 
of their 2006 mental health condition. We set up a more restrictive approach with the goal of shortening the time gap between observations of mental health and of employment outcome. We consider individuals having been at least 3 years in employment between 2007 and 2010 (and not in employment precisely only in 2010). By reducing this time gap, there should be less likelihood of unobserved heterogeneity linked to specific events between 2006 and 2010 that influence the results. The results are presented in Table 5 and Table 6 . These results confirm those of the main specifications, namely that the employment outcome should not have been influenced too much by the time frame.

Table 5: Effect of anxiety disorders on employment between 2007 and 2010

\begin{tabular}{|c|c|c|c|c|c|c|c|c|}
\hline \multirow{3}{*}{ Variable } & \multicolumn{4}{|c|}{ Men } & \multicolumn{4}{|c|}{ Women } \\
\hline & \multicolumn{2}{|c|}{ Probit } & \multicolumn{2}{|c|}{ Biprobit } & \multicolumn{2}{|c|}{ Probit } & \multicolumn{2}{|c|}{ Biprobit } \\
\hline & Coeff. & SER & Coeff. & SER & Coeff. & SER & Coeff. & SER \\
\hline $\begin{array}{l}\text { Mental health in } 2006 \\
\text { Suffering from anxiety disorder }\end{array}$ & $-.10 * * *$ & .02 & $-.13 * * *$ & .04 & -.04 & .02 & -.07 & .06 \\
\hline Control variables & \multicolumn{2}{|c|}{ Yes } & \multicolumn{2}{|c|}{ Yes } & & & \multicolumn{2}{|c|}{ Yes } \\
\hline $\mathbf{N}$ & \multicolumn{4}{|c|}{2,368} & \multicolumn{4}{|c|}{2,613} \\
\hline
\end{tabular}

Note: Marginal effects, standard errors in italics. ***: significant at 1\%, **: significant at 5\%, *: significant at $10 \%$.

Source: Santé et Itinéraire Professionnel survey, individuals aged 20-55 in employment in 2006.

Table 6: Effect of depressive episodes on employment between 2007 and 2010

\begin{tabular}{|c|c|c|c|c|c|c|c|c|}
\hline \multirow{3}{*}{ Variable } & \multicolumn{4}{|c|}{ Men } & \multicolumn{4}{|c|}{ Women } \\
\hline & \multicolumn{2}{|c|}{ Probit } & \multicolumn{2}{|c|}{ Biprobit } & \multicolumn{2}{|c|}{ Probit } & \multicolumn{2}{|c|}{ Biprobit } \\
\hline & Coeff. & SER & Coeff. & SER & Coeff. & SER & Coeff. & SER \\
\hline \multicolumn{9}{|l|}{ Mental health in 2006} \\
\hline Suffering from depressive episode & $-.10 * * *$ & .02 & $-.12 * * *$ & .04 & $-.04 * *$ & .02 & $-.11 * * *$ & .04 \\
\hline Control variables & \multicolumn{2}{|c|}{ Yes } & \multicolumn{2}{|c|}{ Yes } & \multicolumn{2}{|c|}{ Yes } & \multicolumn{2}{|c|}{ Yes } \\
\hline $\mathbf{N}$ & \multicolumn{4}{|c|}{2,368} & \multicolumn{4}{|c|}{2,613} \\
\hline
\end{tabular}

Note: Marginal effects, standard errors in italics. ***: significant at 1\%, **: significant at 5\%, *: significant at $10 \%$. Source: Santé et Itinéraire Professionnel survey, individuals aged 20-55 in employment in 2006.

\section{DISCUSSION AND CONCLUSION}

This study demonstrates that a degraded mental health condition directly reduces the ability of men to remain in employment four years later. This is the case after controlling for socioeconomic characteristics, employment and the nature of past professional careers. These results are in line with those of the literature, and they further provide original perspectives on French data about the capacity of mentally-impaired workers to keep their jobs. Considering GAD and MDE separately suggests that the disabling nature of mental health is reflected in both indicators. These results are also supported by specific estimations for the period 20072010, which in part allow us to deal with the events occurring between 2006 and 2010.

Our study provides new elements for considering sex differences in the impact of mental health, and it confirms the importance of mental health when considering work and employment. We 
implement a unique instrumental variable strategy relying on different instrument sets for men and women, according to the most relevant mental health determinants for each group. To our knowledge, no other study linking mental health with employment outcomes made use of such framework. The results obtained with this differentiated strategy are more precisely estimated (the instruments being more correlated with our mental health indicators and less subject to challenge the exogeneity hypothesis). Yet, it is noteworthy that these results remain mostly unchanged (same sign and relatively comparable significance levels) when implementing a more conventional approach with similar instrument sets for both genders. It seems that it would be appropriate to continue implementing public policies that support people with mental disorders who wish to enter the labour market or to help them remaining into employment while also extending these policies to cover common mental disorders such as depressive episodes and anxiety disorders, of which the prevalence is high in France. Consequently, accompanying measures for workers could be helpful in keeping them in the labour market. Notably, the French Psychiatry and Mental Health Plan of 2011-2015 affirms the importance of preventing job stress and taking measures to make it easier for people with mental disorders to retain their jobs and return to work.

In following this first step, several extensions may be appropriate. Our results demonstrate a varying impact of mental health on job retention according to gender. This difference may be explained by differences in social norms related to the perception of mental disorders and employability, by differences in the disease severity, or by differentiated paths during the 20062010 period. As a consequence, the differences we find could very well be explained, at least partly, by the fact that two different realities may be depicted by a man and a woman who both declare facing anxiety disorders or depressive episodes. Notably, it is widely acknowledged that, compared to women, men have a tendency to declare such issues only when their troubles are already at a more advanced stage (in terms of the intensity of symptoms). This intuition seems to be confirmed by the robustness checks on mental health thresholds. It should be noted that - even though our indicators are relatively robust against false positives - this is not so much the case for false negatives (as explained in Appendix 4). It would also be interesting to determine the paths of transmission for these differences.

\section{ACKNOWLEDGEMENTS}

The authors wish to thank, for their comments, Thibault Brodaty (Érudite, Upec), Eve Caroli (Leda-Legos, PSL-Université Paris Dauphine), Laetitia Challe (Érudite, Upem), Emmanuel 
Duguet (Érudite, Upec), Roméo Fontaine (Leg, University of Burgundy), Maarten Lindeboom (Vrije Universiteit Amsterdam), Yannick L’Horty (Érudite, Upem), Aurélia Tison (Aix Marseille University), Judit Vall-Castello (Pompeu Fabra University) and Yann Videau (Érudite, Upec). The authors also wish to thank Caroline Berchet (Ined), Marc Collet (Drees), Lucie Gonzalez (Haut Conseil de la Famille), Sandrine Juin (Érudite, Upec and Ined) and Nicolas de Riccardis (Drees) for responding to the requests on an earlier version. We also would like to thank the editor and the two anonymous reviewers of LABOUR: Review of Labour Economics and Industrial Relations The authors obviously remain solely responsible for inaccuracies or limitations in their work. 


\section{REFERENCES}

Akashi-Ronquest, N., Carrillo, P., Dembling, B., and Stern, S. (2011) 'Measuring the biases in self-reported disability status: evidence from aggregate data', Applied Economics Letters, 18: 1053--1060.

Alexandre, P.K., and French, M.T. (2001) 'Labor Supply of Poor Residents in Metropolitan Miami, Florida: The Role of Depression and the Co-Morbid Effects of Substance Use', J Ment Health Policy Econ, 4: 161--173.

Altonji, J.G., Elder, T.E., and Taber, C.R. (2005) 'Selection on Observed and Unobserved Variables: Assessing the Effectiveness of Catholic Schools', Journal of Political Economy, 113: 151--184.

Artazcoz, L., Benach, J., Borrell, C., and Cortès, I. (2004) 'Unemployment and mental health: understanding the interactions among gender, family roles, and social class', Am J Public Health, 94: 82--88.

Bahu, M., and Mermilliod, C. (2014) 'Le choix d'indicateurs de santé : l'exemple de l'enquête SIP 2006', Drees Working Paper.

Banerjee, S., Chatterji, P., and Lahiri, K. (2015) 'Effects of Psychiatric Disorders on Labor Market Outcomes: A Latent Variable Approach Using Multiple Clinical Indicators: Psychiatric Disorders and Labor Market Outcomes', Health Economics.

Barnay, T. (2010) 'In which ways do unhealthy people older than 50 exit the labour market in France?', The European Journal of Health Economics, 11: 127--140.

Barnay T., Duguet E., Le Clainche C., Narcy M., Videau Y. (2015) 'The Impact of Handicap on Occupations: a Comparison Between Public and Private Sectors', Annals of Economics and Statistics, 119-120: 39--64.

Barnay, T. (2016) 'Health, work and working conditions: a review of the European economic literature', The European Journal of Health Economics, 17: 693--709.

Bartel, A., and Taubman, P. (1986) 'Some Economic and Demographic Consequences of Mental Illness', Journal of Labor Economics, 4: 243--256.

Beck, F., Cavalin, C., and Maillochon, F. (2010) 'Violences et santé en France : état des lieux', Drees, Documentation Française.

Chang, H.-H., and Yen, S.T. (2011) 'Mental health and employment of the elderly in Taiwan: a simultaneous equation approach', Pacific Economic Review, 16: 504--519.

Chatterji, P., Alegria, M., and Takeuchi, D. (2011) 'Psychiatric disorders and labor market outcomes: Evidence from the National Comorbidity Survey-Replication', Journal of Health Economics, 30: 858--868.

Dahal, A., and Fertig, A. (2013) 'An econometric assessment of the effect of mental illness on household spending behavior', Journal of Economic Psychology, 37: 18--33.

Dalgard, O.S., Dowrick, C., Lehtinen, V., Vazquez-Barquero, J.L., Casey, P., Wilkinson, G., Ayuso-Mateos, J.L., Page, H., Dunn, G., and The ODIN Group (2006) 'Negative life events, social support and gender difference in depression: A multinational community survey with data from the ODIN study', Social Psychiatry and Psychiatric Epidemiology, 41: 444--451.

De Riccardis, N. (2012) 'Traitements de la non-réponse et calages pour l'enquête santé et itinéraire professionnel de 2010', Drees Working Paper. 
Devaux, M., Jusot, F., Sermet, C., and Tubeuf, S. (2008) 'Hétérogénéité sociale de déclaration de l'état de santé et mesure des inégalités de santé', RFAS, 2008: 29--47.

Etilé, F., and Milcent, C. (2006) 'Income-related reporting heterogeneity in self-assessed health: evidence from France', Health Economics, 15: 965--981.

Ettner, S., Frank, R., and Kessler, R. (1997) 'The Impact of Psychiatric Disorders on Labor Market Outcomes', Cambridge, MA: National Bureau of Economic Research.

Frijters, P., Johnston, D.W., and Shields, M.A. (2014) 'The effect of mental health on employment: evidence from australian panel data: effect of mental health on employment', Health Economics, 23: 1058--1071.

Gannon, B. (2009) 'The influence of economic incentives on reported disability status', Health Economics, 18: 743--759.

Greve, J., and Nielsen, L.H. (2013) 'Useful beautiful minds-An analysis of the relationship between schizophrenia and employment', Journal of Health Economics, 32: 1066--1076.

Guiho-Bailly, M.-P., Bertin, C., Dubre, J.-Y., Lancien, N., Machefer, J., and Parent, D. (2009) 'Rapport subjectif au travail: sens des trajets professionnels et construction de la santé Rapport final, Tome 1', Drees Working Paper.

Hamilton, V.H., Merrigan, P., and Dufresne, É. (1997) 'Down and out: estimating the relationship between mental health and unemployment', Health Economics, 6: 397--406.

Jusot, F., Khlat, M., Rochereau, T., and Serme, C. (2008) 'Job loss from poor health, smoking and obesity: a national prospective survey in France', Journal of Epidemiology \& Community Health, 62: 332--337.

Kelly, B.J., Lewin, T.J., Stain, H.J., Coleman, C., Fitzgerald, M., Perkins, D., Carr, V.J., Fragar, L., Fuller, J., Lyle, D., et al. (2011) 'Determinants of mental health and well-being within rural and remote communities', Soc Psychiatry Psychiatr Epidemiol, 46: 1331--1342.

Kessler, R.C., Greenberg, P.E., Mickelson, K.D., Meneades, L.M., and Wang, P.S. (2001) 'The effects of chronic medical conditions on work loss and work cutback', J. Occup. Environ. Med., 43: $218--225$.

Leach, L.S., Christensen, H., Mackinnon, A.J., Windsor, T.D., and Butterworth, P. (2008) 'Gender differences in depression and anxiety across the adult lifespan: the role of psychosocial mediators', Social Psychiatry and Psychiatric Epidemiology, 43: 983--998.

Lindeboom, M., and Kerkhofs, M. (2009) 'Health and work of the elderly: subjective health measures, reporting errors and endogeneity in the relationship between health and work', Journal of Applied Econometrics, 24: 1024--1046.

Llena-Nozal, A., Lindeboom, M., and Portrait, F. (2004) 'The effect of work on mental health: does occupation matter?', Health Econ, 13: 1045--1062.

Lollivier, S. (2006) 'Économétrie avancée des variables qualitatives', Economica.

Marcotte, D.E., Wilcox-Gök, V., and Redmond, D.P. (2000) 'The labor market effects of mental illness: The case of affective disorders', In The Economics of Disability, (Emerald Group Publishing Limited), 181--210.

Mossakowski, K.N. (2009) 'The Influence of Past Unemployment Duration on Symptoms of Depression Among Young Women and Men in the United States', American Journal of Public Health, 99: 1826--1832. 
Nelson, R.E., and Kim, J.W. (2008) 'Survival of the Fittest: Impact of Mental Illness on Employment Duration', Pharmacotherapy Outcomes Working Paper.

Ojeda, V.D., Frank, R.G., McGuire, T.G., and Gilmer, T.P. (2010) 'Mental illness, nativity, gender and labor supply', Health Economics, 19: 396--421.

Plaisier, I., de Bruijn, J.G.M., Smit, J.H., de Graaf, R., ten Have, M., Beekman, A.T.F., van Dyck, R., and Penninx, B.W.J.H. (2008) 'Work and family roles and the association with depressive and anxiety disorders: Differences between men and women', Journal of Affective Disorders, 105: 63--72.

Shmueli, A. (2003) 'Socio-economic and demographic variation in health and in its measures: the issue of reporting heterogeneity', Soc Sci Med, 57: 125--134.

Zhang, X., Zhao, X., and Harris, A. (2009) 'Chronic diseases and labour force participation in Australia', Journal of Health Economics, 28: 91--108. 


\section{APPENDIX 1: MAJOR DEPRESSIVE EPISODES (MDE)}

The MDE are identified in two stages. First, two questions using filters are asked:

- Over the past two weeks, have you felt particularly sad or depressed mostly during the day, and this almost every day? Yes/No

- Over the past two weeks, have you had almost a constant feeling of no interest in anything, of having lost interest or pleasure in things that you usually like? Yes/No

If one of the two filter questions receives a positive answer, a third question is then asked in order to know the specific symptoms: Over the past two weeks, when you felt depressed and/or uninterested in most things, have you experienced any of the following situations? Check each "yes" answer, several possible positive responses.

- Your appetite has changed significantly, or you have gained or lost weight without having the intention to (variation in the month of $+/-5 \%$ ).

- You had trouble sleeping nearly every night (waking up at night or too early, sleeping too much).

- You talked or moved more slowly than usual, or in contrast, you felt agitated and you had trouble staying in one place, nearly every day.

- You felt tired almost all the time, without energy, almost every day.

- You felt worthless or guilty, almost every day.

- You had a hard time concentrating or making decisions, almost every day.

- You had several dark thoughts (such as thinking it would be better to be dead), or you thought about hurting yourself.

Using the responses, two algorithms are then implemented in accordance with the criteria of the Diagnostic and Statistical Manual (DSM-IV). An individual suffers from MDE if:

- A positive response to two filter questions and four symptoms are listed

- Two positive answers to two filter questions and three symptoms are listed 


\section{APPENDIX 2: GENERALIZED ANXIETY DISORDER (GAD)}

GAD are identified using a similar system of filter questions.

Three questions are asked:

- Over the past six months, have you felt like you were overly concerned about one thing or another? Have you felt overly concerned, worried, or anxious about everyday life problems at work/school, at home or about your relatives? Yes/No

If answer is positive:

- Do you have such concerns almost every day? Yes/No

If answer is positive:

- Is it difficult to control these concerns or do they prevent you from focusing on what you have to do? Yes/No

If the interviewee answers positively to the three filter questions, another question is asked in order to know the specific symptoms: "Over the last six months, when you felt particularly concerned, worried or anxious, did you often happen to ...?":

- feel restless, tense or with nerves on edge?

- experience muscle tension?

- feel tired, weak or easily exhausted?

- have trouble concentrating?

- be particularly irritable?

- have sleep problems (difficulty falling asleep, waking in the middle of the night, waking early or sleeping too much)?

For a person to be considered as suffering from generalized anxiety disorder, he/she must respond positively to the three filter questions; then, afterwards, they must report three of the six symptoms described. This protocol is consistent with that used by the DSM-IV. 


\section{APPENDIX 3: ATTRITION BETWEEN THE TWO WAVES}

Attrition between the 2006 and 2010 waves can induce the selection of a population with specific characteristics. Regarding the first wave characteristics of our sample - specifically their demographic, socioeconomic and health characteristics - there are no significant differences between respondents and non-respondents to the 2010 survey. However, differences in the response rate to the 2010 survey exist according to perceived health status, activity limitations, the declaration of major depressive episodes and the declaration of motion or sleep disorders (De Riccardis, 2012). We therefore established weighting system to reflect this nonresponse, which is calculated using employment situations, urban units, age groups, education, sex and health status. Logit models are used to estimate the response behaviour of interviewees depending on whether or not they actually answered the survey in 2010. This procedure allows identifying homogeneous response groups (HRG) in which the individual probability of answering the survey is equivalent and independent between each HRG. They are then used as sample stratifications, wherein a second sample is then selected with a sample rate equalling the individual probability of responding for each HRG. One can then determine weights assigned to each individual depending on his/her HRG.

Sample calibration allows the use of a sample that matches the characteristics of the general French population. Calibration is performed on the average of the four Quarterly Employment surveys for the year 2006. The variables used are urban units, age groups, education, ethnicity and the number of dwelling inhabitants (De Riccardis, 2012).

Weighting in the SIP survey allows taking into account attrition between the two waves, which is notably related to poor general, physical or mental health status. It also allows matching the sample with the general population based on a number of socio-demographic characteristics. 


\section{APPENDIX 4: MEASUREMENT AND VALIDITY OF MENTAL HEALTH INDICATORS}

The mental health protocol for the SIP survey is based on the Diagnostic and Statistical Manual of Mental Disorders (DSM-IV), created in 1952 by the American Psychiatric Association (APA). It focuses exclusively on mental illnesses, unlike the International Classification of Diseases (Cim-10), which covers all types of disease. In SIP, the modules are comprehensive regarding major depressive episodes (MDE) and generalized anxiety disorder (GAD) from the Mini-International Neuropsychiatric Interview (MINI). The precise construction of MDE and GAD is detailed in Appendix 1 and Appendix 2. Through successive filters, this reduces the number of "false positives", i.e., people wrongly detected as suffering from these disorders, given the diagnostic criteria.

According to the DSM-IV assessed by the MINI, 6.8\% of the surveyed population currently suffers from MDE. Within this population, $45 \%$ experience recurrent depressive disorders. According to these criteria, 5.7\% of the population undergoes GAD. The comparison with the results of the survey "Life Events and Health Status" (EVS) - which was conducted over the same period in the general population and with an identical protocol - revealed extremely close results to those of the SIP survey (Beck et al., 2010). As expected, these results differ from those of the French Mental Health in the General Population survey (11\% of MDE in the past two weeks and 13\% of GAD). Mental Health in the General Population (SMPG) is based on the Cim-10 (International Diseases Classification, version 10) version of the algorithm (not the one based on DSM-IV), and it more easily detects MDE and GAD. Measuring mental health in SIP is consistent with a more restrictive definition (DSM-IV) and seems valid in comparison to similar fields in France.

While the questionnaire on mental disorders makes full use of the nomenclature proposed by the MINI, it has no diagnostic value. It can instead be viewed as diagnostic interviews conducted by an interviewer and based on all the symptoms described by the DSM-IV and Cim10. It must not lead to a medical diagnosis (Bahu and Mermilliod, 2014). However, it appears that according to the results of a qualitative post-survey interview about some indicators used in the SIP survey that included health indicators (Guiho-Bailly et al., 2009), the over-reporting phenomenon (false positives) of mental disorders in the survey is not widespread; while, in contrast, under-reporting (false negative) may occur more often. In studying the impact of mental health on job retention, this would lead to an underestimation of the effect of mental health. 
APPENDIX 5: INSTRUMENTS VALIDATION

Table 7: Effect of instruments on the estimated probability of anxiety disorder

\begin{tabular}{|c|c|c|c|c|c|c|c|c|c|c|c|c|c|c|c|c|}
\hline \multirow{3}{*}{ Variable } & \multicolumn{8}{|c|}{ Men } & \multicolumn{8}{|c|}{ Women } \\
\hline & \multicolumn{2}{|c|}{ Probit } & \multicolumn{2}{|c|}{ Biprobit } & \multicolumn{2}{|c|}{ OLS } & \multicolumn{2}{|c|}{ 2SLS } & \multicolumn{2}{|c|}{ Probit } & \multicolumn{2}{|c|}{ Biprobit } & \multicolumn{2}{|c|}{ OLS } & \multicolumn{2}{|c|}{ 2SLS } \\
\hline & Coeff. & SER & Coeff. & SER & Coeff. & SER & Coeff. & SER & Coeff. & SER & Coeff. & SER & Coeff. & SER & Coeff. & SER \\
\hline \multicolumn{17}{|l|}{ Instruments } \\
\hline Violence during childhood & $.08 * * *$ & .03 & $.08 * * *$ & .03 & $.10 * * *$ & .03 & $.10 * * *$ & .03 & $.07 * * *$ & .02 & $.07 * * *$ & .02 & $.11 * * *$ & .03 & $.11 * * *$ & .03 \\
\hline Marital breakdowns & $.02 * *$ & .01 & $.02 * * *$ & .01 & $.03 * * *$ & .01 & $.03 * * *$ & .01 & - & - & - & - & - & - & - & - \\
\hline Raised by a single parent & - & - & - & - & - & - & - & - & $.02 *$ & .01 & $.02 *$ & .01 & $.04 * *$ & .02 & $.04 * *$ & .01 \\
\hline \multicolumn{17}{|l|}{ Ind. characteristics in 2006} \\
\hline Age & -.00 & .03 & -.00 & .03 & -.00 & .00 & -.00 & .00 & .01 & .01 & .01 & .01 & .01 & .01 & .01 & .01 \\
\hline Age squared & .00 & .01 & .00 & .01 & .00 & .00 & .00 & .00 & -.00 & .00 & -.00 & .00 & -.00 & .00 & -.00 & .00 \\
\hline In a relationship (ref.: Single) & $-.02 * *$ & .00 & $-.02 * *$ & .00 & $-.03 * *$ & .01 & $-.03 * *$ & .01 & $-.03 * * *$ & .01 & $-.03 * * *$ & .01 & $-.04 * * *$ & .01 & $-.04 * * *$ & .01 \\
\hline Children (ref.: None) & .01 & .00 & .01 & .00 & .01 & .01 & .01 & .01 & .00 & .02 & .00 & .02 & .00 & .02 & .00 & .02 \\
\hline \multicolumn{17}{|l|}{ Education (ref.: French bac.) } \\
\hline - $\quad$ No diploma & -.04 & .01 & -.04 & .01 & -.02 & .02 & -.02 & .02 & -.02 & .03 & -.02 & .03 & -.02 & .03 & -.02 & .03 \\
\hline - $\quad$ Primary & .01 & .01 & .01 & .01 & .01 & .01 & .01 & .01 & .01 & .01 & .01 & .01 & .01 & .01 & .01 & .01 \\
\hline - $\quad$ Superior & -.01 & .03 & -.01 & .03 & .00 & .01 & .00 & .01 & .02 & .02 & .02 & .02 & .02 & .02 & .02 & .02 \\
\hline \multicolumn{17}{|l|}{ Employment in 2006} \\
\hline \multicolumn{17}{|l|}{ Prof. cat. (ref.: Blue collar) } \\
\hline - Farmers & -.06 & .04 & -.06 & .04 & $-.05^{*}$ & .03 & $-.05^{*}$ & .03 & .00 & .05 & .00 & .05 & -.00 & .06 & -.00 & .06 \\
\hline - Artisans & -.03 & .02 & -.03 & .02 & $-.04 *$ & .02 & $-.04 *$ & .02 & -.01 & .04 & -.01 & .04 & -.00 & .04 & -.000 & .04 \\
\hline - $\quad$ Managers & .01 & .01 & .01 & .01 & .01 & .01 & .01 & .01 & -.03 & .03 & -.03 & .03 & -.03 & .02 & -.03 & .02 \\
\hline - $\quad$ Intermediate & .00 & .01 & .00 & .01 & -.00 & .01 & -.00 & .01 & -.01 & .02 & -.01 & .02 & -.01 & .02 & -.01 & .02 \\
\hline - $\quad$ Employees & -.01 & .01 & -.01 & .01 & -.01 & .01 & -.01 & .01 & -.01 & .02 & -.01 & .02 & -.01 & .02 & -.01 & .02 \\
\hline \multicolumn{17}{|l|}{ Activity status (ref.: Private) } \\
\hline - $\quad$ Public sector & -.01 & .01 & -.01 & .01 & -.01 & .01 & -.01 & .01 & .00 & .01 & .00 & .01 & .00 & .01 & .00 & .01 \\
\hline - $\quad$ Self-employed & $.04 * *$ & .02 & $.04 * *$ & .02 & $.05 * * *$ & .02 & $.05 * * *$ & .02 & -.02 & .03 & -.02 & .03 & -.02 & .03 & -.02 & .03 \\
\hline \multicolumn{17}{|l|}{ Act. sector (ref.: Industrial) } \\
\hline - $\quad$ Agricultural & -.00 & .02 & -.00 & .02 & -.00 & .02 & -.00 & .02 & .02 & .04 & .02 & .04 & .02 & .04 & .02 & .04 \\
\hline - $\quad$ Services & .01 & .01 & .01 & .01 & .01 & .01 & .01 & .01 & -.01 & .02 & -.01 & .02 & -.01 & .02 & -.01 & .02 \\
\hline Part time (ref.: Full-time) & -.03 & .03 & -.03 & .03 & -.02 & .02 & -.02 & .02 & $.03 * *$ & .01 & $.03 * *$ & .01 & $.03 * *$ & .01 & $.03 * *$ & .01 \\
\hline \multicolumn{17}{|l|}{ Professional Career Path } \\
\hline Maj. of empl. in long jobs & -.01 & .01 & -.01 & .01 & -.01 & .01 & -.01 & .01 & -.01 & .01 & -.01 & .01 & -.01 & .01 & -.01 & .01 \\
\hline Stable career path & .00 & .01 & .00 & .01 & -.00 & .01 & -.00 & .01 & -.01 & .01 & -.01 & .01 & -.01 & .01 & -.01 & .01 \\
\hline Rho & \multirow{3}{*}{\multicolumn{2}{|c|}{2,368}} & $.42 * *$ & .18 & & & & & & & .46 & .39 & & & & \\
\hline $\begin{array}{l}\text { F-stat } \\
\mathbf{N}\end{array}$ & & & & & & & \multirow{2}{*}{\multicolumn{2}{|c|}{$\begin{array}{l}13.82 \\
2,368 \\
\end{array}$}} & \multirow{2}{*}{\multicolumn{2}{|c|}{2,613}} & & & & & \multirow{2}{*}{\multicolumn{2}{|c|}{$\begin{array}{l}12.53 \\
2,613 \\
\end{array}$}} \\
\hline $\mathbf{N}$ & & & & & & & & & & & & & & & & \\
\hline
\end{tabular}

Note: Marginal effects, standard errors in italics. ***: significant at 1\%, **: significant at 5\%, *: significant at $10 \%$.

Source: Santé et Itinéraire Professionnel survey, individuals aged 20-55 in employment in 2006. 
Table 8: Effect of instruments on the estimated probability of depressive episode

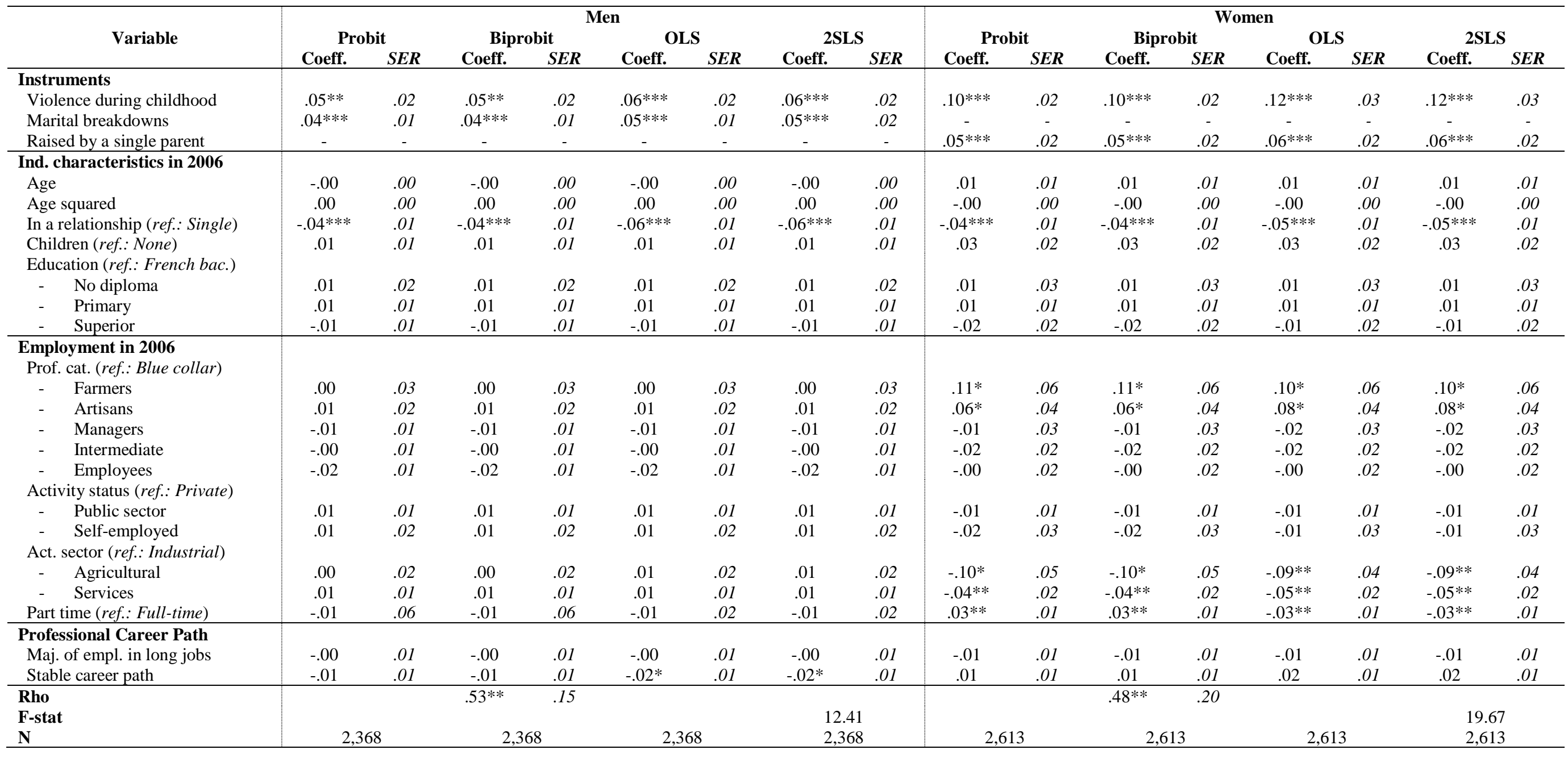

Note: Marginal effects, standard errors in italics. ***: significant at 1\%, **: significant at 5\%, *: significant at $10 \%$.

Source: Santé et Itinéraire Professionnel survey, individuals aged 20-55 in employment in 2006. 